\title{
Infrastructure, equity and urban planning: a just process for the allocation of benefits and burdens
}

\section{Daniel Durrant}

This chapter asks first, what is infrastructure or more importantly infrastructures as the physical artefacts and technologies are inextricably intertwined with complex economic, social and ecological systems. This is central to the first dimension of equity considered, distributional equity. Infrastructures allocate different 'goods' spatially and to population groups therefore to understand the impacts of infrastructures upon distributional equity it is important to understand what exactly they are and what goods they produce. Second, planning and the planning of infrastructures highlight the importance of procedural equity and equality of input into the process. The next section examines definitions of equity and their application to urban planning and urban infrastructure. This draws upon three philosophical analyses of the concept and ways in which it has been recently applied to develop principles that could reshape the way infrastructure is planned and provided. A framework is developed to illustrate the ways in which the planning of urban infrastructure might be used to establish more equitable outcomes. This is based upon a vertical axis along which procedural inputs influence the way the planning process allocates distributional outputs. These are distributed along a horizontal axis of benefits and burdens with the planning process used as a means of establishing minimum and maximum permissible thresholds. As the examples of infrastructure that has been planned and delivered specifically to address issues of social equity are few and far between the chapter is interspersed with examples of where some dimensions have been addressed either explicitly or indirectly.

\subsection{Introduction}

As a dimension of sustainability social equity is something of a hydra. Achieving equity in one area can see multiple inequalities rear their heads in others as urban infrastructure produces a multitude of potential inequalities planners must account for (Beatley, 1988; Thomopoulos et al., 2009). Furthermore, concepts of sustainability introduce additional dimensions with the need for equity between generations and even species. There is no one comprehensive solution and different infrastructures affect equity in different ways, indeed no single definition works in all circumstances. Definitions are dependent upon the ethical framework adopted (Beatley, 1988). This chapter considers four different ethical frameworks most relevant to equity in infrastructure critiquing the dominant utilitarian framework and then exploring the potential of Rawlsian, egalitarian and the Aristotelian capabilities theory. Appraising the consequences for social equity in government programs such as 
the funding of infrastructure projects is increasingly a legal duty (Legislation .gov.uk 2010) in the UK, with the need to identify and measure the impact on specific groups within society (Transport for London, 2004) or upon different income groups (HM Treasury, 2011). Yet as is often the case it is the economic arguments and justifications that push their way to the fore. However, for some time now a paradigm shift has been underway. The modernist assumptions that the comprehensive, universal provision as the route to technological progress have 'splintered', in part due to the privatization of, formally public infrastructure providers (Graham and Marvin, 2001). Since the 1980's the global trend in public policy has been towards infrastructure as an opportunity for private investment, often at the expense of its role in public provision, Britain's first Private Finance Initiative (PFI) funded infrastructure project the controversial Skye Bridge being a good example (see Monbiot, 2004). However, new concepts are in the process of forming and new forms of infrastructure are called for (Brown, 2014). The challenge in this case is, in the first instance a conceptual shift that is far from complete. The overarching aim of this chapter is to illustrate the inadequacies of current conceptions of equity still influential in urban planning and the planning of urban infrastructure and to introduce the reader to alternatives. Much of this work cites developments in transport planning as this is one infrastructural system where the issues are visibly played out however concern with issues such as the 'digital divide' (van Dijk, 2016) indicate concerns across a range of infrastructures. It is not taken as given that a low carbon future is also an equitable one. Consequently, what is called for is a clearly understood and expressed set of principles governing the planning and provision of urban infrastructure.

\subsection{What is infrastructure?}

Most definitions of infrastructure take in the organisational as well as the physical nature of the concept. The term has been traced back to its origins in French railway planning first entering English usage via the military (Marshall, 2015). Its etymology as the basis or underlying structure of a system points towards a dual role as something that both shapes and directs yet at the same time lacks complete visibility: 'something grey behind a chain-link fence' (Brand, 2009). Yet in the transmission of goods, people, power and information over increasingly vast distances it has formed the basis of an industrial and information revolution. It underpins a model of development supported by a financial ecosystem from the World Bank and the various development banks through to states and private investors seeking to capitalise on the benefits infrastructure investment has historically generated. It is a model that has produced huge aggregate benefits although the distribution of these benefits has been far from equal. Furthermore, the burdens have

\footnotetext{
${ }^{1}$ The term refers to the distinction between those that do and those that do not have access to new communications technologies (such as the internet, mobile telephony and digital broadcasting). It may refer to groups in society or specific places and may be the product of economic, educational or spatial inequalities.
} 
often fallen upon groups and environments least able to resist urbanisation and the extraction of resources (such as urban land) and, it appears increasingly, upon future generations.

At the extreme the burdens imposed by infrastructure include the sequestration of land and the health consequences of externalities such as noise and air pollution. The former, in contemporary societies is governed by some legal protections for landowners although historically it has not always been the case and groups such as tenants will often have fewer rights. Even today where land use or rights are not protected or overridden by powerful interests large infrastructure projects such as the Three Gorges Dam in China can be the cause of significant displacement of populations (Gellert and Lynch 2003). More immediate, albeit temporary, burdens such as noise, pollution, community severance can be imposed during the construction, operation and decommissioning of urban infrastructure.

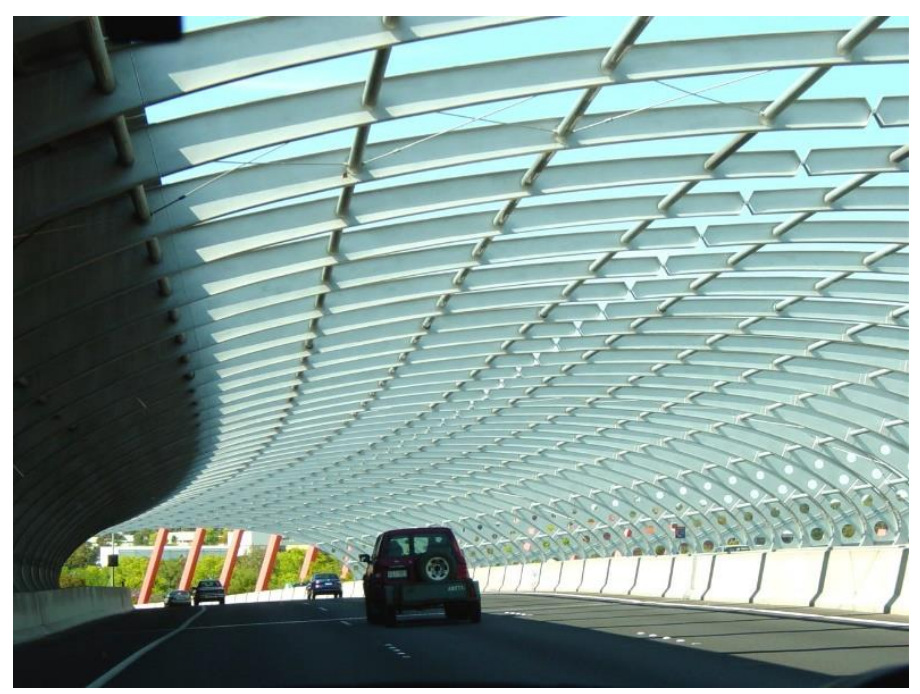

Figure 1.1 Acoustic barriers on the Tullamarine Freeway, Melbourne Australia (Photo; Atlantica). For some burdens such as noise there are engineering solutions available assuming sufficient mitigation costs are included in the initial project appraisal. Others such as the impact of automobile emissions and the particulate matter they produce on air quality may require policy action to limit certain vehicles and to encourage modal shift to less polluting forms of transport.

If the pressing issue of the inequality between generations and species is to be meaningfully addressed then infrastructures and the planning of infrastructure must play a part in directing a shift from high to low carbon emissions and reducing resource consumption (Giddens, 2011). It is beyond the scope of this chapter to comment on the feasibility of such a challenge, instead it focuses on the question of whether it can be achieved in an equitable way. This is particularly relevant; as 
people are lifted out of poverty and given access to basic infrastructure questions of equity become more rather than less important. The role played by the hard infrastructures that provide sanitation, power, transport and communication and the soft infrastructure that provide health, education and law and order have all been massively successful in raising the standards of living for the least well off in many parts of the world, China being the prime example. It has seen the most rapid rise in economic and social development of any major economy lifting more than 800 million people out of poverty and achieving the Millennium Development Goals by 2015 (World Bank, 2016). In some ways China has followed a similar, albeit accelerated, path to countries in the Global North. High levels of investment in infrastructure combine with economic development to produce widespread increases in the standard of living: a pattern common to other rapidly growing East Asian Economies such as Thailand and Vietnam (Asian Development Bank,2005). Whilst there is still much to do with infrastructure deficits plaguing the Global South this model has been largely successful, up to a point. The 'environmental story' of East Asian infrastructure development, for example, is far less positive (ibid).

Arguably, this vision of technological progress, a vision underpinned by infrastructure, has reached its zenith as citizens are increasingly sceptical of the benefits (Beck, 1992) and averse to the burdens imposed. As the consequences of a resource intensive, fossil fuel based model of development are widely acknowledged to be unacceptable the existing forms of infrastructure that underpin this model will have to adapt, adjust and in some cases, switch to something new. In parallel to this shift is the rise of democracy, civil society and human rights, often enshrined in international law. This gives citizens who are asked to bear the costs of infrastructure increased opportunity to challenge that imposition. Furthermore, it affects the appetite of funders and investors to become involved in projects that may have demonstrable and unjustifiable consequences for social equity: just as they would for infrastructure that is environmentally destructive or fails to meet its economic or technical performance criteria.

Understanding the urban dimension of infrastructure is both revealing of what exactly infrastructure is and problematic as it confines the issues to a particular place. On the one hand cities contain concentrations of wealth and poverty and so are ideal locations for attempts to narrow the gap between the two. Infrastructure can define cities with infrastructures providing power, heat and gas often originally provided at the municipal level and in some of the Nordic countries, for example, municipal ownership is still common. In the UK at least, many rural areas are not connected to either networks providing natural gas and waste water treatment, likewise it is common for rural homes to rely on local water sources rather than being incorporated into the networks that serve urban areas. However, infrastructural networks also link rural and urban areas. Polluting and higher risk coal and nuclear power generation has traditionally been sited away from cities but connected by transmission infrastructure to those areas where the power is required. Food and its provision through transport infrastructure has visibly shaped a city like London's urban form with wide roads enabling the flow of fresh meat 'on the hoof' into the 
city centre (Steel, 2008). The way that infrastructure reflects this relationship between rural and urban helps to underline some of the challenges when this relationship is understood through the lens of social equity as by definition rural areas are where deficits, such as high speed broadband, persist even in the Global North.

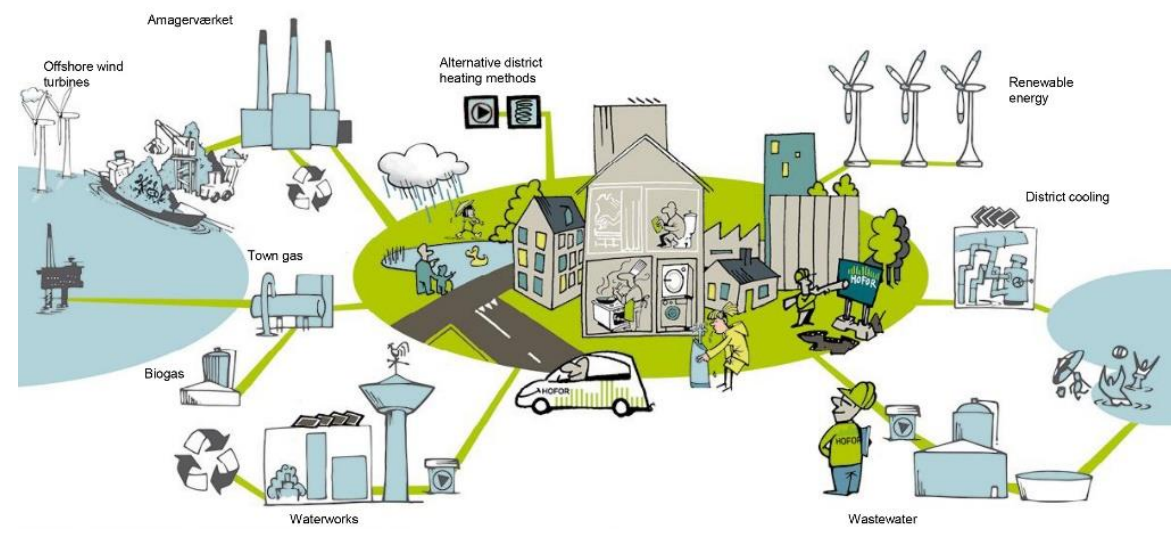

Fig. 1.2 Copenhagen's HOFOR utility company, an example of how municipal ownership is still common in the Nordic countries. (Reproduced from HOFOR 2016)

It is important, however, to get beyond conceptions of infrastructures as purely physical artefacts. Given the focus of urban planning is on the allocation and governance of urban space it is hardly surprising that the focus tends to be on the spatial manifestation of infrastructure. This is where it competes with other urban land uses and has an impact on the lives of urban citizens. Since Ebenezer Howard's vision of a planned community supported by its infrastructure there has always been a utopian strand in urban planning that sees the organization of space as the pursuit of some greater good. In Howard's plans infrastructure was always hard (waterways and rail links) and soft (care homes and educational facilities). In a resource constrained world there is increasing expectation that infrastructure is also multi-purpose. An example of this is the integration of transport and communications infrastructure or waste water and community facilities (Brown, 2014) that has always occurred to an extent, however the expectations of this are increasing given the resources new infrastructure consumes. As with physical functions, the integration of social infrastructures into the design of the physical artifacts adds to the overall value of the whole infrastructural system. Beyond this, in our information society infrastructures sit within infrastructures. Take for example micro-payment and trad- 
ing systems that sit within and depend upon mobile telephony and internet infrastructure. Furthermore, as the infrastructural dimensions of environmental systems are being acknowledged this broadens the definition of infrastructure further still.

There are good reasons for including social systems in any definition of infrastructure. They may be more flexible and adaptable and in terms of equity they can go some way towards overcoming the limitations imposed by the physical structures. The way that the rail operators in the UK have systems to support disabled access to trains through ramps and human support may not be a perfect solution. It is second best when compared to the full disabled accessibility that is required for new infrastructure, however it does enable some access to a system where the resources available for upgrading facilities are limited and progress is slow. Finally, what is in many ways more significant is the way that technologies, such as those employed in infrastructural systems sit within relatively stable socio-technical systems. These are known as 'regimes' (Rip and Kemp, 1998) made up of structures and actors, legislation, public and private sector institutions, the skills and knowledge necessary to produce different technologies and crucially social norms and values. Rather than something that is external to social systems infrastructural technologies can be seen to coevolve mutually shaping and being shaped by the socio-technical regimes of which they are a part. Technological transitions of the type required to shift to lower carbon forms of infrastructure can be brought about by internal or external pressures on these wider socio-technical regimes (Geels, 2002). Pressure to change technologies can come from a wide variety of sources; economic or demographic changes and crucially shifts in the norms and values of societies (Smith et al, 2005). Understanding infrastructures as more than just transport, communications or energy technologies is central to understanding how new infrastructural technologies coevolve to both produce and reflect societal shifts.

\subsection{What kind of goods are infrastructures?}

There are three important generalisations that can be made in defining what infrastructures are and the type of benefits and burdens they distribute (Frishman, 2012). First, government is still heavily involved either funding, granting consent and regulation often all three. Second, infrastructures tend to be, at least theoretically, open to everyone albeit often above a certain cost threshold. Third, there are considerable beneficial 'spillovers' that go beyond the individual users. It is these benefits that suggest the definition of merit goods in that they are deemed by society to be of sufficient value that they should be provided to all. The market alone is in many cases insufficient_(this can be due to high levels of risk and sunk capital for large transport infrastructure or poor returns on high installation costs for broadband in rural and hard to serve urban areas such as older tower blocks) therefore they may require some form of public provision or subsidy. This is particularly true of the infrastructures necessary to shift from high to lower carbon emitting forms of energy and transport in circumstances where markets favour the former. The concept of merit goods draws the allocation of resources into the equation as if certain goods 
are to be actively provided rather than passively enabled then the resources must be found and (re)distributed to ensure the desired level is achieved.

When considering distributional equity in relation to infrastructure one should consider what is it that infrastructure provides or even what are the infrastructures that should be distributed equitably? For some it may be a question of resources whilst for others it is the opportunities enabled by infrastructure that ought to be the focus of measures to increase equity. With infrastructure the question of resources is ever present. Resources are required to construct new infrastructure, maintain the systems that enable existing infrastructures to function and also to decommission or repurpose those that have become obsolete. The decision to allocate resources to one piece of infrastructure incurs opportunity costs as it may be at the expense of another infrastructural choice. Where the burdens of providing those resources (be that finance, land or human capital) fall is considered in some detail below. One final, often neglected, resource is trust . Given the allocation of resources are often 'up front' based on projected returns in the future there is a need to maintain the trust of those who provide them, the public. This is trust that the projections are accurate, that mitigation will be delivered and of a sufficient standard and that the claimed benefits will actually materialise. Given the depressing history of, particularly the larger (Flyvbjerg et al., 2003), infrastructure projects this is a key resource that is often depleted. 


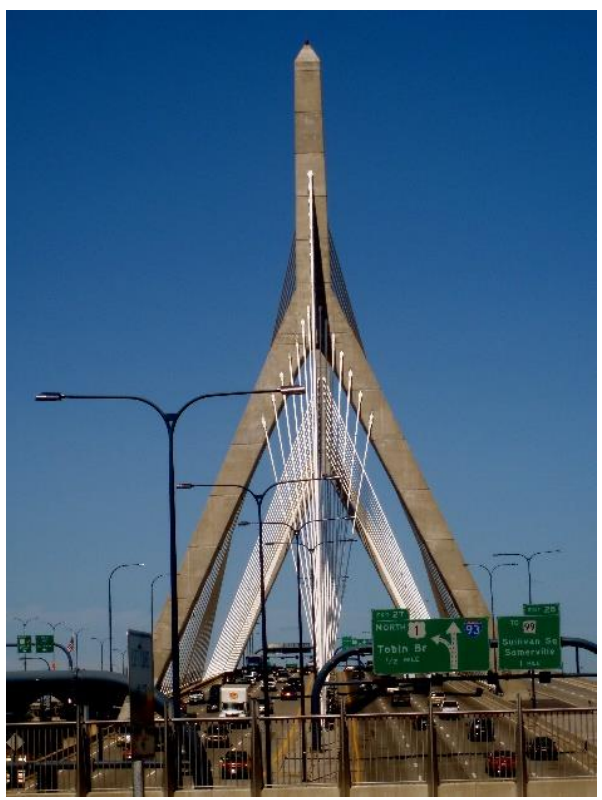

Figure 1.3 Zakim Bridge, the 'Big Dig' (Photo; Leigh Housholder). Altschuler and Luberoff, (2003) describe the practice of inaccurate cost estimates for major infrastructure projects as a 'tragedy of the commons' that undermines faith in the project and government as a whole. An example of the type of project they cite is Boston's Central Artery Tunnel the 'Big Dig'. The project was highly controversial and marred by an overspend of 155 percent of the original cost estimate, a delay of three years combined with allegations of corruption, prosecutions for fraud and poor workmanship that saw a section of the ceiling collapse in 2006 killing a motorist (OMEGA Centre, 2016).

What must also be considered is the benefits of infrastructure. These can be actual benefits such as rising land values or new transport links, and with basic infrastructures freedom from the risks of waterborne diseases and intermittent power supply. However, they can also be potential benefits such as those derived from mobility or access to communication technologies. Finally, it is also important to consider when the burdens of infrastructure are distributed. As technologies such as acoustic barriers and tunnel boring improve even large infrastructures can almost disappear in terms of the burdens they impose upon the urban environment. However, there are parts of the lifecycle, such as the construction phase, when there is still considerable potential for disruption even if in the long run the infrastructure improves equity overall. Ten years of construction may appear a small price to pay for a project with national benefits and a sixty year projected lifespan. However from an individual perspective this could mean the formative years of a child's life, primary through to tertiary education spent with increased noise and atmospheric pollution, reduced access to green space and elevated risks due to high volumes of construction traffic. 
Fig. 1.4 Some infrastructure can almost disappear or provide a colorful addition to the urban environment. Recycling and waste shoots in Hammerby Sjöstad. (Image; author's own)
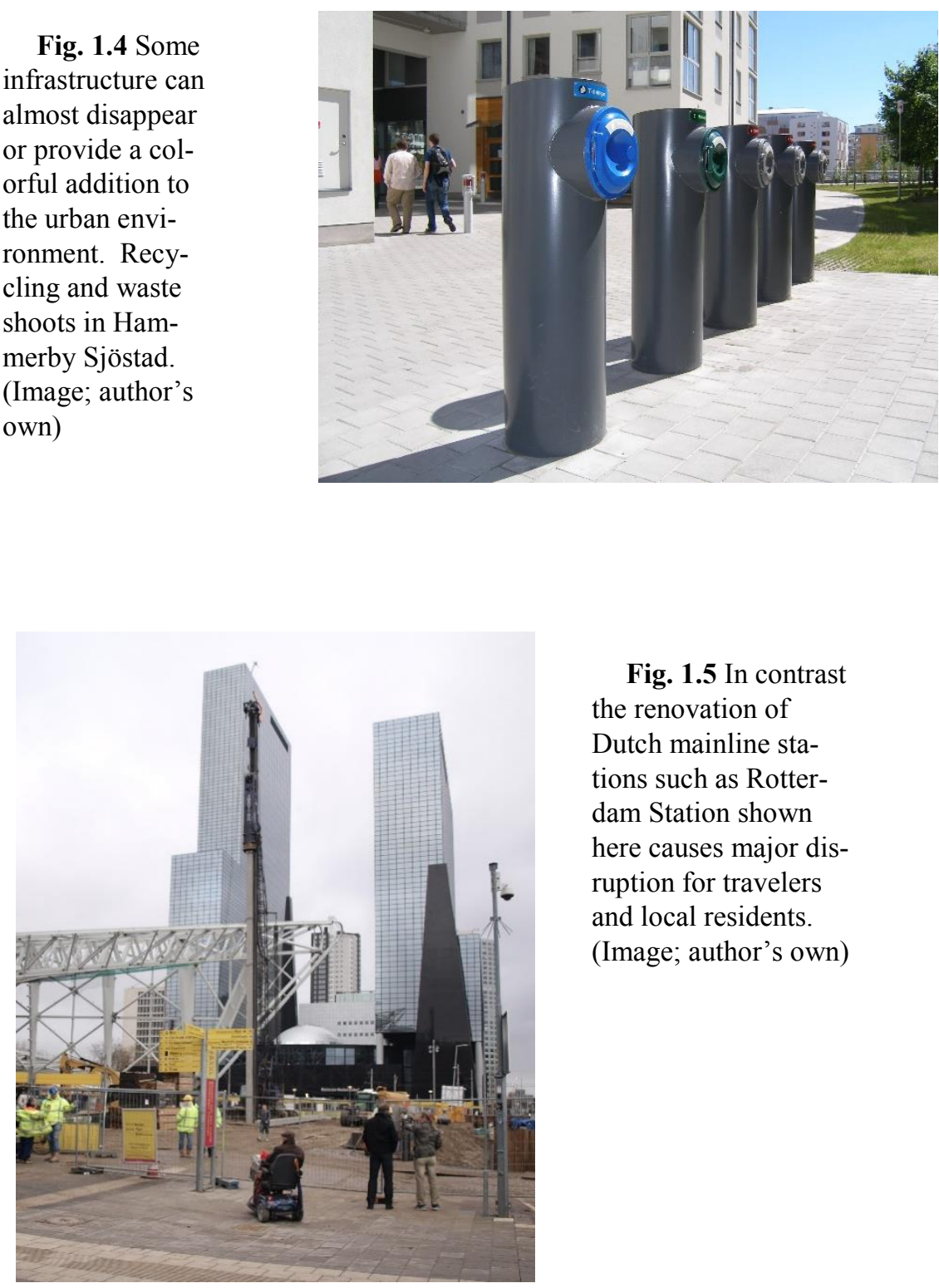

Fig. 1.5 In contrast the renovation of Dutch mainline stations such as Rotterdam Station shown here causes major disruption for travelers and local residents. (Image; author's own)

\subsection{Planning and infrastructure}

The term planning is used in its broadest sense here. Many infrastructures and infrastructure projects have their own, distinct planning and appraisal processes that both construct a justification for projects and concern the timing and allocation of 
resources necessary to move a specific piece of infrastructure from inception to operation. If a 'cradle to cradle' (Braungart and McDonough, 2009) approach is taken then also the decommissioning and reuse of this physical component of the infrastructural system (see figure 1.4). Ideally this should fit with plans concerning the allocation of urban space although unfortunately this is not always the case. Planning, like infrastructures, allocates burdens and benefits and within this process there is considerable scope for inequalities. If the ultimate outputs are to be considered legitimate then there are good grounds for arguing that all those who stand to lose or gain have equal input into the process (Dewey, 1927). This is more than a theoretical issue as failure to consult properly is an area where there is considerable scope for legal challenge ${ }^{2}$. In a democracy, the requirement is generally for the opportunities to participate to be distributed equally or at the very least not closed off to some groups. For such a principle to be maintained it is often the case that considerable additional effort must be made to ensure that excluded groups are given equal opportunity to participate (Planning Aid, 2012).

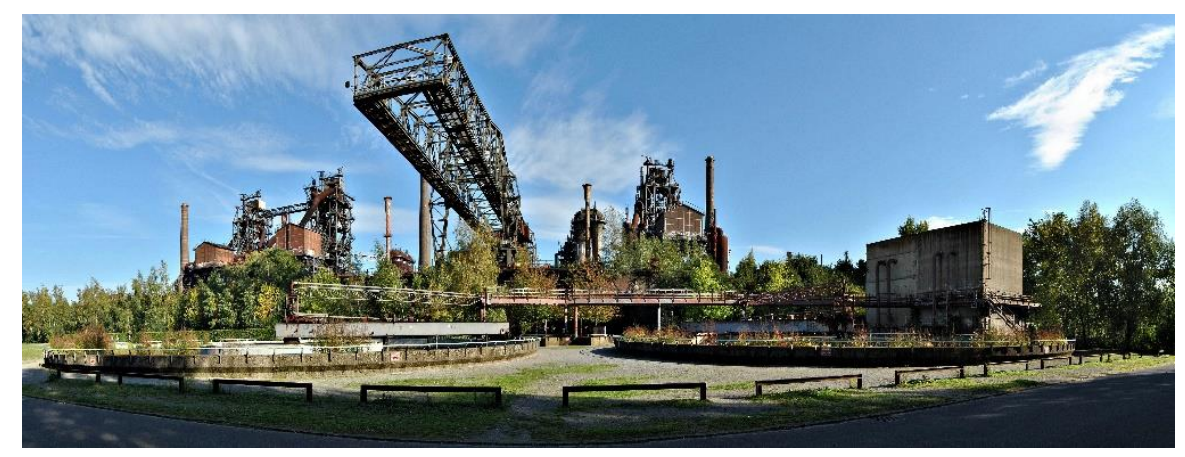

Fig. 1.6 Landschaftpark Duisburg Nord an example of where planning visions and the reuse of the former industrial infrastructure of the Ruhr Valley has aligned (Photo; Carsten) See also (Hall, 2014).

One issue that is particularly acute in planning and even more so in infrastructure planning is the inequalities in the status allocated to different forms of information. The type of knowledge required such as planning, engineering and economics are all the product of years of specialist education and often professional accreditation.

${ }^{2}$ HS2 a proposed high speed rail project in the UK has attracted considerable controversy and several legal challenges. Whilst on the whole the courts in the UK have been unwilling to uphold challenges to the project the one area where opponents have had limited success was in their challenge to the consultation of compensation which was ruled unlawful on the basis that insufficient information was provided and that compensation options were inadequately explained (DfT, 2013). This resulted in HS2Ltd being forced to re-run the compensation consultation. 
It is possible for those lacking such knowledge to purchase the skills of expert consultants but often at a high price. The special status given to these forms of knowledge is often understandable, indeed necessary to protect public safety, yet it also poses problems when this form of expert knowledge such as those used in the appraisal of infrastructure projects discussed in the following sub section, provides the justification for decision making. It can squeeze out or fail to acknowledge the value of 'local knowledge'3 (Yanow, 2003) about the consequences of infrastructure projects for those that must live with them. In addition to this the risks of siloed approaches and individual disciplines defining problems and solutions from a single perspective are well known (Brown, 2014) yet still persistent.

Opening up the 'black box' of infrastructure decision making is difficult to achieve in practice and may still be uncomfortable for some professionals. Access to information is an important issue with confidentiality and commercial sensitivity used to restrict the important knowledge generated by infrastructure projects (OMEGA Centre 2013). On the other hand, the internet and freedom of information legislation can in some respects equalise access to information. There is still one area where the problems of unequal weighting applied to different forms of knowledge within the planning process and particularly the process of infrastructure planning is much harder to address. This is where the black box remains firmly closed, indeed it seeks to become invisible. The values and assumptions contained within it go unacknowledged and are presented as facts. Furthermore, these facts can constrain the options considered and shape the solutions from a limited pallet creating 'narratives of necessity' (Owens and Cowell 2011) that both legitimate the wider political decisions and shape the process of planning and infrastructure appraisal. This not only poses problems from the perspective of equal participation but can also create considerable risks of 'path dependency' (Curtis and Low, 2012) locking in pathways to high carbon emitting forms of infrastructure. This is as the values that tend to be entrenched are the ones that shape conventional approaches such as the appraisal techniques discussed below.

\subsection{Maximising utility}

There is a certain irony that one of the key mechanisms for the appraisal of infrastructure that is increasingly seen as a barrier to more equitable, less environmentally damaging forms of infrastructure was initially percieved as an alternative to pork-barrel infrastructure projects (Shapiro and Schroeder, 2008). The belief was that Cost Benefit Analysis (CBA) provides a rational means of ensuring the benefits

${ }^{3}$ The attachment to certain places and landscapes identified by Patrick DevineWright (2012) and often dismissed by (in this case renewable energy infrastructure) project promoters as NIMBYism (Not in My Back Yard) is an example of the type of local knowledge which if ignored can generate opposition and resulting costs and delays for project promoters. In contrast the Berger Inquiry into the Mackenzie Valley Pipeline in Canada's Northwest Territories is often cited (Torgeson, 2003) as a positive example of the inclusion of local and indigenous knowledge. 
of infrastructure were distributed to society as a whole, rather than to a small group of (sometimes corrupt) individuals. CBA is based on utilitarian principles that assume that the maximization of individual utility will ultimately produce equality. With CBA, this is achieved by aggregation of total benefits, the solution that produces the most benefits for the least cost being the ideal one.

Utilitarian assumptions have long influenced urban planning (Moroni, 2006) and as an appraisal methodology CBA exerts considerable power in shaping the planning and implementation of urban infrastructure. Whilst in many situations the general principle that the benefits of infrastructure should exceed the costs is hard to argue with, the practice of CBA has been widely criticised for the inequalities it produces. As a facet of the 'modernist infrastructural ideal' (Graham and Marvin, 2001) the practice was at least underpinned by some notion of public benefit. However, under neoliberal governance regimes the aggregate economic benefits are increasingly seen as public benefits. Regardless of who the actual recipients are.

Three practices in particular, monetisation of costs and benefits, discounting and (for transport projects) the emphasis on travel time savings, produce considerable inequalities in the way the benefits and burdens of infrastructures are distributed. First, the calculation of the financial costs of some elements of infrastructure projects is not always problematic. Materials, labour and the purchase of land can all be estimated with a sufficient degree of certainty to ensure it is simply a matter of good sense. Where monetisaton becomes more problematic is when it is attached to projected benefits and costs, often some time into an uncertain future. There are problems of validity when such calculations are based upon a further set of assumptions about willingness to pay for a resource (Naess, 2006). A problem that is particularly acute for environmental resources which are often resistant to translation into monetary values. Monetisation of values can reinforce existing inequalities as money itself is not evenly distributed and so a significant cost toone group may be barely noticed by another.

Alongside the monetisation of values there is the practice of discounting which assumes a cost incurred today is greater than one of the same monetary value incurred sometime in the future. This can militate against intergenerational equity in the way it legitimises the passing on of costs to future generations. For this reason a much lower discount rate was adopted in the influential Stern Report (Stern, 2006) into the costs of climate change mitigation. The assumptions embedded within the practice of discounting are also those of increasing prosperity and rising incomes.

Finally, the valuation of travel time savings in transport infrastructure is another example of the way that the benefits of infrastructure are often unequally distributed. A contemporary example of this can be found in plans for a high speed rail connection between London and Birmingham (HS2) in the UK. Benefits are unequally allocated due to a higher estimated value of business user's time. This is despite the majority of predicted users of the railway being non-business travelers with 70 per cent travelling for leisure trips and non-business related reasons (HS2Ltd/DfT, 2011). The consequences of this has been the design of the infrastructure has been shaped by the need to facilitate rapid travel. This has been at the 
expense of the urban environment as the design requires a large amount of demolition surrounding Euston station. This particular case illustrates a further, questionable practice used in CBA. It is certainly the true that with increasingly complex and interconnected infrastructures the calculation of all costs and benefits is problematic. However, it is also highly political which costs are calculated. In addition to the demolition of what is largely social and low cost housing as a result of HS2 construction will cause years of disruption for local businesses. The problem is particularly acute on Drummond St an area characterised by predominantly Bengali owned shops and restaurants. These are costs excluded from the CBA of what has already proved to be a contentious project. Opponents also argue that the compensation costs to property owners are inadequate, an indication that even when the methodology itself is not challenged the selection of inputs into the analysis is never value free.

\subsection{What is equity}

A further challenge when seeking to deliver more equitable forms of urban infrastructure is to be clear about what form of equity is desired. As the application of CBA shows an assumption of equity (or more precisely the assumption that a single conception of equity is sufficient) can lead to unjust and unequal outcomes. In the following section alternatives to the utilitarian calculations of equity are identified. Each has in one way or another been applied to the planning and development of urban infrastructures and each is likely to skew that development towards different ends.

\subsection{Meeting the needs of the least well off: Rawls' difference princi-} ple

It is first useful to consider why equity ought to be an important dimension and, as is argued here, an explicit aim of any attempt to deliver more sustainable urban infrastructures. There is sound empirical evidence that more equal societies are better in terms of physical and mental health, educational attainment and trust in others (Wilkinson and Pickett, 2011). This is in the face of growing inequality (Dorling, 2011) and the increasing redistribution of wealth upwards (Picketty, 2014). The evidence points to equality, or at least reduced inequality, as a better state of affairs for all concerned. This is the argument that equality is a rational choice as seen in Rawls (1971) arguments for greater equality and better outcomes for the least well off. Rawls argues that Cetus Paribus a rational individual would choose a more equal society if they were unaware of their own likely position in that society, operating behind what he called a 'veil of ignorance'. This provides an argument for the reduction of inequalities yet Rawls also acknowledges the reality, indeed the desirability of some inequality the level of which is limited by Rawls' 'difference principle'. This states that;

"the higher expectations of those better situated are just if and only if they work as part of a scheme which improves the 
expectations of the least advantaged members of society."

(Rawls 1971

This may appear abstract yet it has been influential on public policy making and has been effectively applied as a principle for restricting the use of the private car beyond the point it impinges upon pedestrian accessibility (Tyler, 2004). Not all believe Rawls basic principles can be applied directly as they relate to the basic institutions of society rather than specific policy or infrastructural decisions (Martins, 2017). Others however, argue that they can guide actions such as efforts to minimise disruption or linking the provision of affordable housing to infrastructure provision whilst acknowledging their limitations in mandating action that directly or exclusively benefits the least well off (Beatley, 1988). What the application of Rawlsian principles achieve is the establishment of threshold levels in the distribution of the burdens of infrastructure below which it is not permissible to fall.

\subsection{Establishing minimum thresholds: Capabilities}

Beyond the rationalist approach adopted by Rawls there is another, essentialist view that is important to acknowledge. This is the argument that equality in some areas is important in itself. Important here is the work of Martha Nussbaum and Amatya Sen on basic capabilities. These are a set of essential of features human life that have a special claim to political support and protection. These include bodily health, friendship, control of one's environment and the ability to live with other species (Nussbaum, 1997) to select those most clearly related to the provision of infrastructure. These capabilities are indivisible; their essential nature means that it is not acceptable to trade them off against each other or against other desirable ends. A clear example of the type of policy this prohibits would be support for infrastructure that trades health against wealth, even assuming the economic gain is equally distributed ${ }^{4}$. A key feature of the capabilities approach is the way that it establishes basic threshold levels of capabilities below which a 'good human life' (Nussbaum, 1992) is not possible.

Whilst Rawls provides limits below which actions should not fall, the capabilities approach provides thresholds that compel action. They have been used as a basis for arguments about gender inequalities in the design of pedestrian and public transport infrastructure (Robeyns, 2011) inequalities facing those with disabilities (Tyler, 2006) and can contribute to accessibility appraisal (van Wee \& Roeser,

\footnotetext{
${ }^{4}$ Whilst in practice such calculations are rarely overt and can be masked behind practices such as CBA one can find examples, particularly in the Global South where little weight is given to the health impacts of new road infrastructure (Klopp, 2012). However in the Global North, where arguably the need for basic economic development is less pressing there is still considerable spending on road infrastructure despite the known health and environmental costs (see Metz, 2008) with action on air quality particularly slow in the UK.
} 
2013). Such an approach is potentially costly particularly in retrofitting older infrastructure designed and built in an era when little consideration was given to people with disabilities. However, for Nussbaum this is the area where resources ought to be directed before any alternatives that may increase other forms of utility, such as wealth (Nussbaum, 1992). The lifting of all citizens above the threshold level is the key criteria against which policies are measured.

\subsection{Equal distribution of resources: Transport Justice}

The final conception of equity considered moves the discussion on from the establishment of thresholds that either forbid certain patterns in the distribution of the burdens of infrastructure or mandate infrastructure designed to facilitate a certain level of activity. Recent work in the field of transport planning (Martens, 2017) calls for principles of equality to guide the process to ensure the benefits (in this case of the accessibility generated by transport infrastructure) are distributed equally to all. Based upon the work of the egalitarian philosopher Ronald Dworkin the argument is that the key merit good distributed by a transport system is accessibility. The concept refers to a person's potential to interact and the actual amount of their interactions that are enabled by transport infrastructure of all types. It is also dependent upon personal attributes such as wealth, ability and ownership of a vehicle and finally it includes a contextual or spatial dimension as different locations have different levels of accessibility.

In contrast to traditional approaches to transport planning that place demand, and meeting demand, at the centre of the planning process this approach places people at the centre. Traditional focus on demand (reflected in the path dependency discussed above) ensures more resources are devoted to establishing a vicious circle in which the infrastructure reflects increased demand and, expands thereby creating yet more demand. Transport justice explicitly limits the public resources that can be devoted towards the expansion to transport infrastructure; and also the private resources that can be appropriated through compulsory purchase. This is through a planning process in which population groups are identified by their spatial location, their accessibility is defined, alongside an acceptable minimum threshold for accessibility. This minimum threshold or 'domain of sufficiency' is acknowledged as political and something that should be established by democratic deliberations. Albeit deliberations informed by a knowledge base utilising data on the actual benefits currently allocated such as levels of employment, degree of social isolation and access to health care. Where this approach differs from the other two described is that it explicitly inhibits public expenditure on infrastructure that benefits the most well off. It is not prohibited it is simply that such infrastructure should be self-financing. Take for example an airport express link, the cost of construction and maintenance would be funded by the ticket price possibly in combination with a subsidy from the airport operator. No public subsidy, use of compulsory purchase powers or grant of land would be available. In practice, it may result in such infrastructure becoming unviable or at least much conservative in their aspirations with the potential to limit excessive resource consumption. 


\subsection{Inputs and Outputs}

Part of the challenge of more equitable infrastructure provision is a shift to what are arguably more just conceptions of equity than the utility based approach embodied within CBA, the modernist paradigm and the neoliberal approach that has replaced it. The solutions above provide a conceptual and normative framework that justifies a reallocation of resources towards more equitable forms of infrastructure provision. Based upon this framework this penultimate section sketches out and illustrates a model of the way in which the planning process might enable these conceptions of equity to shape the provision of future infrastructures.

\subsection{More equitable planning}

If, as is argued here, infrastructures are reflective of the values of the societies that produce them then it is the planning process, through which those inputs are made. Some of those values may be hidden in the assumptions of the experts managing the process whilst others may leak in from the political milieu in which decisions are made. Equity is a critical principle at this stage in the process if the voices of all those who are likely to bear the burdens are to be given equal weight. This does not mean that all burdens are to be treated equally. Acceptable limits to the burdens imposed and benefits allocated by the construction and operation of infrastructure is something that needs to be established by an open democratic process to ensure that the voices of the most vocal or most powerful do not exclude others. An open process ${ }^{5}$ ought also to be able to tease out some of the assumptions implicit in the methodologies employed in project appraisal. It should also be remembered that the process itself is a burden to some and a benefit to others. The professionals that manage the process, public bureaucrats and particularly the private sector consultants sometimes have a vested interest in extending the planning process. The same is true of groups seeking to delay outputs that they may wish to avoid. Again, equity as a principle ought to go some way to ensuring that such strategic behaviour is exposed for what it is.

Planning as a process ultimately allocates benefits and burdens and there is a broad literature on fairness in decision making and planning (Dryzek, 1995; Healey, 1995; Forrester, 1999; Innes and Booher, 2004) as well as practical examples of attempts to achieve it (Just Space, 2014). In the early stages of planning where the

\footnotetext{
${ }^{5}$ There is insufficient space to go into detail on what such a process might look like although in many cases it goes beyond a simple series of public meetings or an instrumental 'consultation' exercise. These may well form part of the process however in areas such as appraisal where the details are technical in nature what may be called for are citizens juries or 'mini-publics' (Mackenzie and Warren, 2012) where a smaller group of citizens is given an opportunity to interrogate the assumptions and practices in more detail.
} 
problems infrastructure is conceived to resolve are defined unequal can become iniquitous if the voices of those who bear the burdens are excluded or marginalised through tokenistic consultation. What is added here is an explicit role in establishing the boundaries of acceptability, both minimum and maximum levels. Where these are and whether or not they have been exceeded may not always be immediately apparent. Consequently, what is called for is a more tentative process of implementation, one that allows for a periodic opening up of the processes of implementation to ensure an equitable distribution is maintained. The outputs may in themselves not distribute burdens and benefits equally, with good reason. The expressed purpose of some piece of urban infrastructure may be to address an existing inequality or identified deficit. Overall, though, the outcomes ought to be an equal distribution of the benefits and burdens something that calls for a strong clearly expressed concept of equity to shape the process.

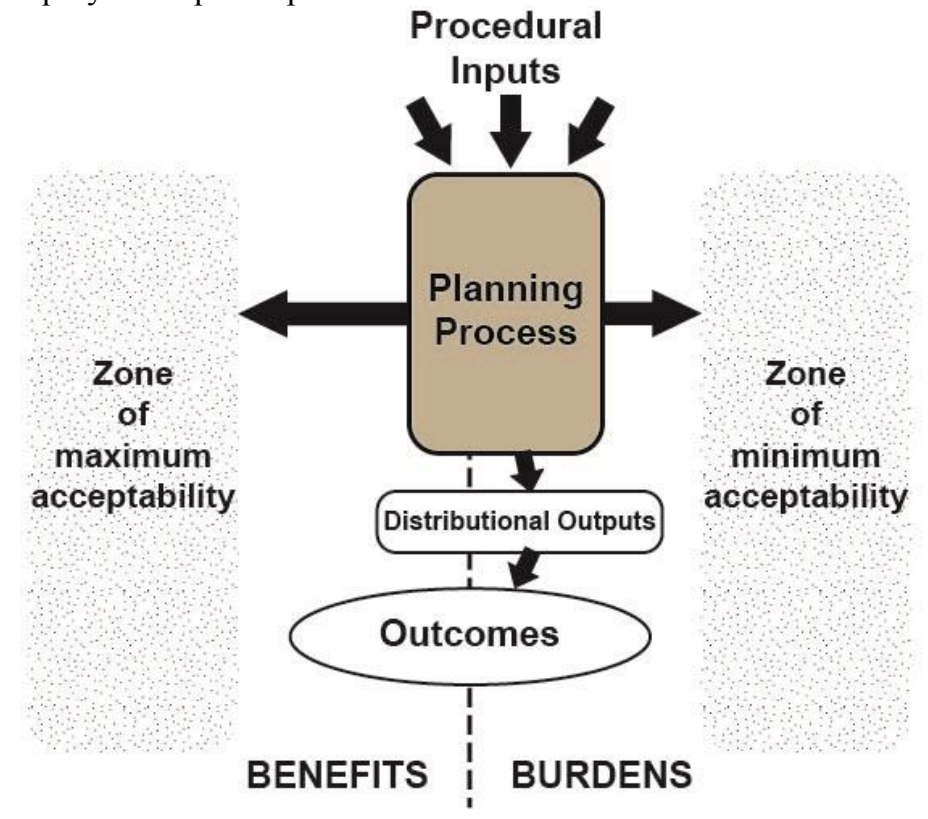

Fig. 1.7 How a planning process might deliver a more equal allocation of benefits and burdens.

\subsection{Equity in the distribution of burdens}

Given the complexities it is perhaps unsurprising the limited progress that has been made in the production of infrastructures that explicitly address issues of equity. This is not to discount significant achievements such as the ongoing work to 
provide basic infrastructure to parts of cities in the Global South such as the informal settlements where it is often lacking, or the widespread improvements in disabled access. Important work on social exclusion in transport in the UK has seen the concept operationalised and applied by regional transport providers only to see schemes designed to address social exclusion fall foul of the current climate of fiscal austerity due to loss of subsidy (Lucas, 2012). Community ownership of energy infrastructure offers possibilities; however, this tends to be at the margins and often a rural phenomenon in the UK, albeit with the picture somewhat brighter in countries such as Denmark, Germany and Austria (Walker, 2008). Once energy infrastructure such as gas pipelines reverts to the national level the problems of technocratic styles of governance and economic imperatives tend to reassert themselves (Groves et al., 2016). Adaptations to the methodologies such as CBA that govern the process suggest that it may be possible to retain, albeit within a further layer of ethical consideration, one that is more sensitive to context and issues such as equity and fairness (van Wee \& Roeser, 2013). Further adaptations have also sought to include social and environmental values within CBA (Fujiwara and Campbell, 2011). Whereas others argue the solution lies in alternatives such as Multi Criteria Analysis (Thomopoulos et al., 2009) that have proved successful in selecting locations for urban green infrastructure (Gül, et al., 2006).

There are some examples cited of infrastructure that does achieve some benefit in terms of social equity. Amsterdam Metro, a costly and controversial project, does improve transport accessibility for neighbourhoods to the North of the city addressing existing shortfalls (Martens, 2017). As an example of a 'disruptive technology' (Flores Dewey, 2016) from the field of transport planning Bus Rapid Transit (BRT) appears to offer a shift away from the car dominated urban infrastructure reflective of an earlier epoch. Developed in its current form in Latin America, it is a clear example of a socio-technical system as it represents a hybrid of different transport and ticketing technologies, legislation to achieve segregated bus lanes and human capital in the form of the skills to maintain and drive the low emissions vehicles required for these high frequency bus services. Its advocates see this technology as facilitating a shift away from the private car and embedding sustainable transport within the urban form (Munoz and Paget-Seekins, 2016). In contrast to more costly fixed transport links it is more flexible, based on re-using the road network, its network of high quality stations can provide complementarity with other forms of infrastructure such as public conveniences. Furthermore, it has the potential, if not always realised (Flores Dewey, 2016), to interact with the informal paratransit networks often used by the poor (Sagaris, 2016). Yet even here the tendency towards a conflictual, paternalistic approach to consultation and implementation has been noted and contrasted with the more coproductive strategies of civil society initiatives to promote cycling infrastructure (ibid). 


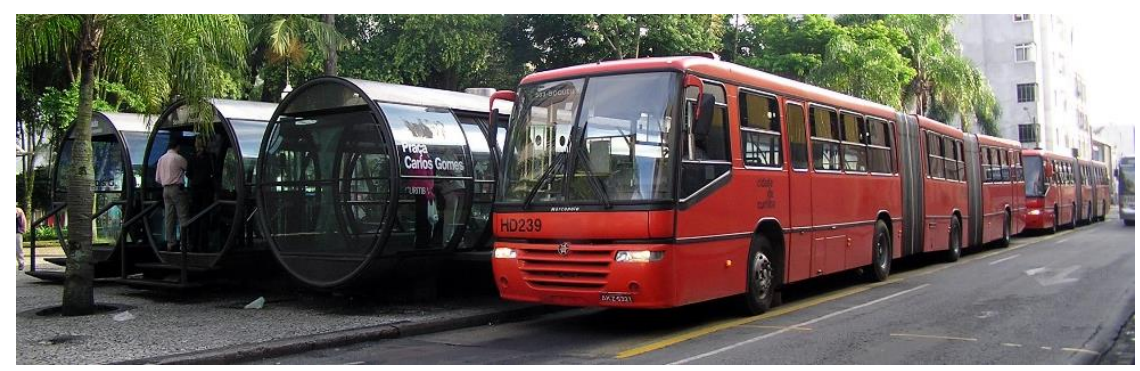

Fig. 1.7 Curitiba’s BRT system. (Photo; Morio)

\subsection{Conclusion}

If there is something to be salvaged from the modernist ideal of infrastructure (Graham and Marvin, 2001) then perhaps it is the concept of comprehensiveness or put another way equality. In the Global North we have come to accept the fact that infrastructural technologies are in place to ensure basic services such as power, clean water and sanitation are provided almost equally to all areas and individuals. The problems of equality here are less in the physical systems than in the management and institutional systems that still, too often, exclude or penalise the most vulnerable. Ensuring the parts of the world where such systems are not in place of the world are brought up to a minimum threshold is still a noble aim. Yet with other infrastructures we have come to accept a level of inequality which is ultimately unjustifiable (Martens, 2017). An indication that in the Global North there is still a way to go and even, as infrastructures such as BRT show, lessons that can be learnt from the Global South. Whilst the focus on urban planning in this chapter has meant the examples drawn upon tend to focus upon transport infrastructures as these are the ones that most concern urban planning given the way they consume and also open up urban space for development. Nevertheless, the gap between digital and transport infrastructures is however rapidly closing with the development of selfdriving cars and the increasing interest of technology companies in the management of public transport (Harris, 2016). The need for guiding principles is, if anything, increasing given that the emerging forms of infrastructure contain a plethora of assumptions that shape the way the benefits they provide and the burdens they ask the public as a whole to bear are allocated. If infrastructure underpins the form of development adopted by modern societies then through the processes of planning it also reflects the values of the societies that produce it. In turn these values are embedded within the physical structures. They are projected into and shape the societies of the future. Equity, between genders, groups and those of different sexual orientations is an increasingly significant principle of contemporary societies. Therefore, if equality of access is already established for some infrastructures and is theoretically possible for others (Martens, 2017) then why should this principle not shape the infrastructure and societies of the future? 


\section{References}

Altschuler, A. and Luberoff, D. (2003) Mega-Projects: The changing politics of urban public investment. The Brookings Institute.

Asian Development Bank (2005) Connecting East Asia:

A New Framework for Infrastructure, Asian Development Bank, The International Bank for Reconstruction and Development / The World Bank, and Japan Bank for International Cooperation

Beatley, T., 1988. Equity and distributional issues in infrastructure planning: a theoretical perspective. In: Stein, J.M. (Ed.), Public Infrastructure Planning and Management. Sage, Newbury Park, pp. 208-226.

Beck, U. (1992) Risk Society: Towards a new modernity. Sage.

Brand, R. (2010) Whole Earth Discipline: An Ecopragmatist Manifesto. Atlantic Books.

Braungart, M and McDonough, W. (2009) Cradle to Cradle. Remaking the Way We Make Things. Vintage.

Brown, H. (2014) Next Generation Infrastructure: Principles for postindustrial public works. Island Press.

Curtis, C. and Low, N. (2012) Institutional Barriers to Sustainable Transport. Ashgate.

Devine-Wright, P. (2013). Explaining "NIMBY" Objections to a Power Line: The Role of Personal, Place Attachment and Project-Related Factors. Environment and Behavior, 6(45), 261-781.

Dewey, J. (1927) The Public and its Problems. George Allen and Unwin Ltd: London.

DfT (2013) HS2 Judicial Review - the challenges explained. Department for Transport.

Dorling, D. (2010) Injustice: Why social inequality persists. Polity Press. Bristol. 
Dryzek, John S. (1995) Discursive Democracy: Politics, Policy, and Political Science. Cambridge University Press.

Forester, J. (1999) The Deliberative Practitioner: Encouraging Participatory Planning Processes. MIT Press.

Flores Dewey, O. (2016) "BRT as a tool for negotiated re-regulation" pp 51-73 in Restructuring public transport through Bus Rapid Transit: An international and interdisciplinary perspective. Munoz, J, C. and Paget Seekins, L (Eds) Polity Press.

Flyvbjerg, B. Bruzelius, N and Rothengatter, W. (2003) Megaprojects and Risk: An Anatomy of Ambition. Cambridge University Press.

Frischmann, B.M. (2012). Infrastructure - The Social Value of Shared Resources. Oxford University Press.

Fujiwara. D and Campbell, R. (2011) Valuation Techniques for Social Cost-Benefit Analysis: Stated Preference, Revealed Preference and Subjective Well-Being Approaches A Discussion of the Current Issues. HM Treasury/Department of Work and Pensions.

Geels, F. W. (2002). Technological transitions as evolutionary reconfiguration processes: a multi-level perspective and a case-study. Research Policy, 31(8-9), 1257-1274. http://doi.org/10.1016/S0048$\underline{7333(02) 00062-8}$

Gellert, P.K. and B.D. Lynch (2003) Mega-projects as displacements. International Social Science Journal (55)175, 15-25.

Graham, S and Marvin, S. (2001) Splintering Urbanism: Networked Infrastructures, Technological Mobilities and the Urban Condition. Routledge Chapman \& Hall.

Giddens, A. (2011) The Politics of Climate Change. 2nd Revised edition edition. Polity Press.

Groves, C., Yakovleva, N., \& Munday, M. (2013). Fighting the pipe: neoliberal governance and barriers to effective community participation in energy infrastructure planning. Environment and Planning C: Government and Policy, 31, 340-356. http://doi.org/10.1068/c11331r 
Gül, A., Gezer, A., \& Kane, B. (2006). Multi-criteria analysis for locating new urban forests : An example from Isparta, Turkey, 5, 57-71. http://doi.org/10.1016/j.ufug.2006.05.003

Hall, P. (2014) Good Cities, Better Lives: how Europe discovered the lost art of urbanism. Routledge.

Harris, M. (2016) Secretive Alphabet division funded by Google aims to fix public transit in US https://www.theguardian.com/technology/2016/jun/27/google-flow-sidewalk-labs-columbus-ohio-parkingtransit Accessed 21st October 2016.

Healey, P. (1995) Discourses of integration: making frameworks for democratic urban planning. pp 251-273 In Managing Cities: the new urban context (Eds) Healey, P.Cameron, S. Davoudi, S. Graham, S and Mandanipour, A. John Wiley and Sons.

HM Treasury (2011) The Green Book https://www.gov.uk/government/uploads/system/uploads/attach-

ment data/file/220541/green book complete.pdf Accessed 31st October 2016.

HOFOR (2016) HOFOR: Greater Copenhagen Utility http://www.hofor.dk/wp-content/uploads/2016/09/hofor greater cph utility.pdf Accessed 2nd November 2016.

HS2Ltd/DfT (2011) Economic Case for HS2. The Y Network and London - West Midlands February 2011. HS2 Ltd/Department for Transport.

Innes, J. E., \& Booher, D. E. (2004). Reframing public participation: strategies for the 21st century. Planning Theory \& Practice, 5(4), 419436. http://doi.org/10.1080/1464935042000293170

Just Space (2016) https://justspace.org.uk/2014/11/06/just-space-critical-of-infrastructure-plan-2050/ Accessed $1^{\text {st }}$ November 2016.

Legislation.gov.uk (2010) Equality Act 2010 http://www.legislation.gov.uk/ukpga/2010/15/contents (Accessed 22nd November 2016) 
Klopp, J. M. (2012). Towards a Political Economy of Transportation Policy and Practice in Nairobi. Urban Forum, 23(1), 1-21. http://doi.org/10.1007/s12132-011-9116-y

Lucas, K. (2012). Transport and social exclusion: Where are we now? Transport Policy, 20, 105-113. http://doi.org/10.1016/j.tranpol.2012.01.013

Mackenzie, M, K. and Warren, M, E. (2012) Two trust-based uses of minipublics in democratic systems. Pp 95-125 Deliberative Systems (Eds) Parkinson, J. and Mansbridge, J. Cambridge University Press.

Marshall, A. (2015) Why the Word 'Infrastructure' Replaced 'Public Works' http://www.governing.com/columns/eco-engines/gov-the-wordinfrastructure.html (Accessed 31st October 2016)

Martens, K. (2017) Transport Justice: Designing fair transportation systems. Routledge.

Metz, D. (2008)The Limits to Travel: How far will you go? Earthscan: Lonson, Stirling VA.

Monbiot, G. (2004) A Scandal of Secrecy and Collusion http://www.monbiot.com/2004/12/29/a-scandal-of-secrecyand-collusion/ (Accessed $14^{\text {th }}$ November 2016)

Moroni, S (2006) The Ethics behind Evaluation: Litchfield's approach and Utilitarianism pp 21-31 in Evaluation in Planning. Alexander, E, R. (Ed). Ashgate.

Munoz, J, C. and Paget Seekins, L "The Promise of BRT" pp 1-15 in Restructuring public transport through Bus Rapid Transit: An international and interdisciplinary perspective. Munoz, J, C. and Paget Seekins, L (Eds) Polity Press.

Naess, P. (2006). Cost-Benefit Analysis of Transportation Investment: Neither Critical Nor Realistic. Journal of Critical Realism, 5(1), 32-60. 
Nussbaum, M. C. (1992). Human Functioning and Social Justice : In Defense of Aristotelian Essentialism. Political Theory, 20(2), 202-246.

Nussbaum, M. C. (1997). Capabilities and Human Rights. Fordham Law Review, 66(2), 273-300.

OMEGA Centre (2013) Mega Projects, Executive Summery Lessons for Decision-makers: An Analysis of Selected International Large-scale Transport Infrastructure Projects http://www.omegacentre.bartlett.ucl.ac.uk/wp-content/uploads/2014/11/Mega-Projects-ExecutiveSummary.pdf Accessed 2nd November 2016.

OMEGA Centre (2016) Central Artery Tunnel Project Summaryhttp://www.omegacentre.bartlett.ucl.ac.uk/wp-content/uploads/2014/12/USA_BIG_DIG_SUMMARY.pdf (Accessed $24^{\text {th }}$ November 2016)

Owens, S. And Cowell, R. (2011) Land and Limits: Interpreting sustainability in the planning process. 2nd Edition. Routledge: London and New York.

Piketty, T. (2014) Capital in the Twenty-First Century. Harvard University Press: Cambridge MA.

Planning Aid (2012) Good Practice Guide to Public Engagement in Development Schemes. http://www.rtpi.org.uk/media/6312/Good-Practice-Guide-to-Public-Engagement-in-Development-Scheme-HighRes.pdf Accessed 1st November 2016.

Rawls, J. (1971)A Theory of Justice. Harvard University Press.

Rip, A. \& Kemp, R. (1998) Technological change, in: S. Rayner \& E. L. Malone (Eds) Human Choices and Climate. Climate Change Volume 2 - Resources and Technology, pp. 327-399. Battelle.

Robeyns, I. (2003). Sen'S Capability Approach and Gender Inequality: Selecting Relevant Capabilities. Feminist Economics (Vol. 9). http://doi.org/10.1080/1354570022000078024 
Sagaris, L. (2016) "Strategic Participation for Change" pp 101-127 in Restructuring public transport through Bus Rapid Transit: An international and interdisciplinary perspective. Munoz, J, C. and Paget Seekins, L (Eds) Polity Press.

Shapiro, S. A., \& Schroeder, C. H. (2008). Beyond Cost-Benefit Analysis: A Pragmatic Reorientation. Harvard Environmental Law Review, $32,434-502$.

Smith, A., Stirling, A., \& Berkhout, F. (2005). The governance of sustainable socio-technical transitions. Research Policy, 34(10), 1491-1510. http://doi.org/10.1016/j.respol.2005.07.005

Stern, N. (2006) Stern Review on the economics of climate change http://webarchive.nationalarchives.gov.uk/+/http:/www.hm-treasury.gov.uk/independent reviews/stern_review economics_climate change/stern_review_report.cfm Accessed 2nd November 2016.

Thomopoulos, N., \& Tight, M. R. (2009). Incorporating equity considerations in transport infrastructure evaluation: Current practice and a proposed methodology. Evaluation and Program Planning, 32, 351-359. http://doi.org/10.1016/j.evalprogplan.2009.06.013

Torgeson, D. (2003) Democracy through policy discourse pp113-139 in Deliberative Policy Analaysis: Understanding Governance in the Network Society (Eds.) M, A Hajer and H Wagenaar. Cambridge University Press.

Transport for London (2004) Equality Impact Assessments (How to do them. http://content.tfl.gov.uk/eia-06-04.pdf Accessed 31st October 2016.

Tyler, N. (2004). School of Public Policy Working Paper Series. Working Paper 8: Justice in transport policy.

Tyler, N. (2006). Capabilities and Radicalism: Engineering Accessibility in the 21st century. Transportation Planning and Technology, 29(5), 331-358. http://doi.org/10.1080/03081060600917629

van Dijk, J. A. G. M. (2016). Digital Divide Research, Achievements and Shortcomings. Poetics, (August 2006). http://doi.org/10.1016/j.poetic.2006.05.004 
van Wee, B., \& Roeser, S. (2013). Ethical Theories and the Cost-Benefit Analysis-Based Ex Ante Evaluation of Transport Policies and Plans. Transport Reviews, 33(6), 743-760. http://doi.org/10.1080/01441647.2013.854281

Walker, G. (2008). What are the barriers and incentives for community-owned means of energy production and use? Energy Policy, 36(12), 4401-4405. http://doi.org/10.1016/j.enpol.2008.09.032

Wilkinson and Pickett (2011) The Spirit Level: Why Greater Equality Makes Societies Stronger. Bloomsbury Press.

World Bank (2016) China Overview. http://www.worldbank.org/en/country/china/overview (Accessed 22nd November 2016)

Yanow, D. (2003) Accessing local knowledge pp228-247 in Deliberative Policy Analaysis: Understanding Governance in the Network Society (Eds) M, A Hajer and H Wagenaar. Cambridge University Press. 